Research Paper

International Journal of Medical Sciences

ISSN 1449-1907 www.medsci.org 2007 4(4):216-222

CIvyspring International Publisher. All rights reserved

\title{
Association between vitamin I receptor gene haplotypes and chronic periodontitis among Japanese men
}

\section{Mariko Naito ${ }^{1}$, Koichi Miyaki 2 , Toru Naito ${ }^{3}$, Ling Zhang ${ }^{4}$, Keika Hoshi ${ }^{5}$, Asako Hara ${ }^{6}$, Katsunori Masaki 6 , Shugo Tohyama ${ }^{6}$, Masaaki Muramatsu4 ${ }^{4}$, Nobuyuki Hamajima ${ }^{1}$, Takeo Nakayama ${ }^{2}$}

1. Department of Preventive Medicine/Biostatistics and Medical Decision Making, Nagoya University Graduate School of Medicine, 65 Tsurumai-cho, Showa-ku, Nagoya, 466-8550, Japan

2. Department of Health Informatics, Kyoto University School of Public Health, Yoshida konoe-cho, Sakyo-ku, Kyoto, 606-8501, Japan

3. Department of General Dentistry, Fukuoka Dental College, 2-15-1 Tamura, Sawara-ku, Fukuoka, 814-0193, Japan

4. Department of Molecular Epidemiology, Medical Research Institute, Tokyo Medical and Dental University, 2-3-10 Kandasurugadai, Chiyoda-ku, Tokyo, 101-0062, Japan

5. Information Design Section, Center for Information Research and Library, National Institute of Public Health, 2-3-6 Minami, Wako, Saitama, 351-0197, Japan

6. Keio University Hospital, 35 Shinanomachi, Shinjuku-ku, Tokyo, 160-8582, Japan

Correspondence to: Mariko Naito, Tel: +81-52-744-2132, Fax: +81-52-744-2971, E-mail: mnaito@med.nagoya-u.ac.jp

Received: 2007.06.30; Accepted: 2007.08.20; Published: 2007.08.22

Background: The vitamin D receptor (VDR) is involved in a variety of biological processes, such as bone metabolism and modulation of the immune response. Recent findings suggest that the pathway involving bone mineral density-mediated effects is important for the development of periodontitis, but their effects of combined VDR gene polymorphisms have not been confirmed on periodontitis. We assessed the relationship between ApaI, BsmI, and FokI VDR polymorphisms and the risk of severe chronic periodontitis among Japanese adult men.

Materials and Methods: In a cross-sectional study, we examined 97 unrelated healthy Japanese men (mean age: 45.6 years, range: 22-59). A clinical examination was performed at a worksite health checkup, and information was obtained using a self-reported questionnaire. DNA was extracted from whole blood, and the VDR ApaI, $B s m \mathrm{I}$, and FokI polymorphisms were genotyped using polymerase chain reaction.

Results: F-carriers of FokI VDR polymorphisms were less likely to develop severe chronic periodontitis than non-F-carriers $(\mathrm{p}=0.09)$. The ApaI and BsmI VDR polymorphisms did not show significant differences in the alleles or genotypes between the subjects with or without severe chronic periodontitis. The haplotype analysis of the three combined VDR polymorphisms revealed that the Abf homozygote had a notably higher prevalence of severe chronic periodontitis than the others, and adjustments for age, smoking status, number of teeth present, and prevalence of diabetes did not change this association $(\mathrm{OR}=7.5 ; 95 \% \mathrm{CI}=1.6-34.4 ; \mathrm{p}=0.01)$.

Conclusion: The VDR haplotype constructed from the ApaI, BsmI, and FokI polymorphisms is related to the risk of severe chronic periodontitis in Japanese men.

Key words: chronic periodontitis; vitamin D receptor; polymorphism; haplotypes

\section{INTRODUCTION}

Periodontal disease is a chronic infection that requires the presence of specific bacteria for disease initiation and progression. Moreover, genetic factors may play a role in determining the host's response to infection and could account for significant variation in its clinical severity [1].

Vitamin D influences the development of periodontal disease through both immunomodulatory effects and an effect on bone mineral density (BMD) [2,3]. Dietrich et al. [4] reported a statistically significant inverse association between serum $25(\mathrm{OH}) \mathrm{D}_{3}$ concentrations and periodontal disease in people aged 50 years or older. Vitamin D has an important role in bone formation and preservation [5], and several epidemiological studies have reported positive associations between osteoporosis or low bone density and alveolar bone and tooth loss, which suggests that poor bone quality is a risk factor for developing periodontal disease [6-8]. Recent findings suggest that alveolar bone loss in periodontal disease is more pronounced in osteoporotic bone [9] and that the pathway involving BMD-mediated effects is important for the development of periodontitis [4].

The vitamin $\mathrm{D}$ receptor (VDR) is involved in a variety of biological processes, such as bone metabolism and modulation of the immune response, in which it functions as a vitamin $\mathrm{D}_{3}$-dependent transcription factor [10]. Several polymorphisms have been identified in the VDR gene, most of which are 
identified by biallelic variation in restriction enzyme sites. Examples of restriction fragment length polymorphisms (RFLPs) in the VDR gene include Tru9I [11], TaqI [12], BsmI [13], EcoRV [13], ApaI [14], and FokI $[15,16]$. All these RFLPs, except FokI in exon 2, are located between exons 8 and 9. By using the sequencing technique, new polymorphisms such as $C d x 2$ [17] in the promoter region have also been detected.

Morrison et al. [12] found an association between bone mass and polymorphisms of the recognition sites of the restriction enzymes BsmI and ApaI in the 3'-end of the VDR gene, and in addition to the effect on mineral metabolism, several studies have investigated the relationship between the VDR polymorphisms and diseases. The effect of VDR polymorphisms in renal failure has been explored, and Sezer et al. demonstrated that the BsmI polymorphism was related to the decreased recombinant human erythropoietin requirements needed to achieve higher hemoglobin levels among dialysis patients [18]. Associations between VDR polymorphisms and susceptibility and outcome have been indicated in prostate, lung, and colon cancers [19-21]. Zou et al. [20] suggested that VDR polymorphisms of $C d x 2$, FokI, and BsmI were associated with improved survival among squamous cell carcinoma patients with early-stage non-small-cell lung cancer. Furthermore, nephrolithiasis has been suggested as being related to the VDR FokI polymorphism [22].

Some association studies involving the VDR, mostly the TaqI polymorphism and periodontal disease, have been conducted in different ethnic populations and settings $[23,24]$, and a few studies have investigated the effect of VDR ApaI, BsmI, or FokI polymorphism on periodontitis. According these results, the A allele for ApaI and the $\mathrm{f}$ allele for FokI might be correlated with an increased risk of periodontitis $[25,26]$. However, none has confirmed the association between the VDR polymorphism and the risk of periodontal disease. Moreover, few studies have examined their effects on periodontitis, although the effects of combined VDR gene polymorphisms on BMD have been reported [27-29].

Therefore, we examined the relationship between ApaI, BsmI, and FokI VDR polymorphisms and the risk of severe chronic periodontitis among Japanese adult men. A strong association between smoking and periodontal disease has been revealed in several previous studies [30-32]. In Japan, the smoking rate in males is the highest among industrialized countries, while the prevalence in females remains low [33]. We hypothesized that VDR polymorphisms would be associated with periodontal disease as an independent risk factor in spite of smoking. We focused on male subjects in this study.

\section{MATERIALS AND METHODS}

\section{Participants}

The subjects were employees in a Japanese chemical company. This report is a part of a cross-sectional study that was previously reported [34]. A total of 291 male subjects participated. Of these, 97 subjects who gave informed consent for DNA analysis were analyzed. The participants were recruited and examined between September and October 2004. All volunteers signed written consent forms before participating.

The study comprised 97 healthy Japanese males between 22 and 59 years of age (mean age: 45.6 years). A dental examination was conducted as a worksite health checkup. Venous blood samples were obtained before the examination, and weight and height were measured in all subjects. The body mass index (BMI) was computed by dividing the body weight in kilograms by the square of the height in meters. The mean $( \pm S D)$ BMI was $23.3 \pm 3.1 \mathrm{~kg} / \mathrm{m}^{2}$, which is typical for healthy Japanese males. Information on smoking status was obtained using a self-reported questionnaire. Smoking status was assessed and subjects were classified as a "current smoker" or "not a current smoker." A diagnosis of diabetes was made according to the Japan Diabetes Society criteria based on a fasting plasma glucose $\geq 126 \mathrm{mg} / \mathrm{dl}$ and $\mathrm{HbA} 1 \mathrm{c}$ $\geq 6.5 \%$.

Each participant was examined by either of two qualified dentists (K.H. and M.N.), who carried out the dental examinations throughout the study period. The diagnosis of periodontal disease and classification of its severity were established based on the clinical parameters of the Community Periodontal Index (CPI). The two dentists were assigned to subjects at random. Inter-examiner agreement of CPIs between the dentists was tested for seven volunteers before the dental examinations (kappa statistics $=0.77, p=0.03$ ). For CPI assessment, 3, 8, 14, 19, 24, and 30 were measured. Each sextant was designed as either healthy (score 0); bleeding, but no dental calculus detected (score 1); calculus detected, but no pockets (score 2); a probing depth exceeding $4 \mathrm{~mm}$ (score 3 ); or a probing depth exceeding $6 \mathrm{~mm}$ (score 4), according to the highest score recorded at the index teeth. The highest score was recorded as the CPI score of the participant. Severe chronic periodontitis was defined as oral health status with a CPI of 4 . Oral health status with CPIs between 0 and 3 was classified as having no severe chronic periodontitis.

Approval for this study was obtained from the ethics committee of Keio University School of Medicine, Tokyo, Japan.

\section{Genotype determination}

DNA was extracted from whole blood using the phenol/chloroform method. The VDR polymorphism was genotyped using polymerase chain reaction (PCR) followed by melt curve analysis [35] with a LightTyper instrument (Roche Diagnostics, Penzberg, Germany). The primers and probes used for determining the ApaI, BsmI, and FokI single nucleotide polymorphisms (SNPs) in the VDR genes are listed in Table 1. According to the dbSNP for FokI SNPs, rs10735810 was used in this study. 
Table 1. Primer and probe sequences for the three polymorphisms of the VDR gene

\begin{tabular}{|c|c|c|c|c|c|}
\hline No. & SNP name & dbSNP & Polymorphism & Primers and probes & 'sequences \\
\hline \multirow[t]{4}{*}{1} & Apa I & rs 17879735 & $\mathrm{G} / \mathrm{T}$ & Sense primer & 5'-CGGTCAGCAGTCATAGAGG-3' \\
\hline & & & (ambiguity code: $\mathrm{K}$ ) & Antisense primer & 5'-CAGTGTGTTGGACAGGCG-3' \\
\hline & & & & Anchor probe & 5'LCRed640-GGCCCCTCACTGCTCAA-3'phosphate \\
\hline & & & & Sensor probe & 5'-GGGGATAGAGAAGA_AGGCACAGGAGCTCTCAGCT-3'Fluorescein \\
\hline \multirow[t]{4}{*}{2} & Bsm I & rs1544410 & $\Lambda / G$ & Sense primer & 5'-GTGTGC $\Lambda$ GGCG $\Lambda$ TTCGT $\Lambda$-3' \\
\hline & & & (ambiguity code: $\mathrm{R}$ ) & Antisense primer & 5'-TACCCTGCCCGCAAGAAA-3, \\
\hline & & & & Anchor probe & $\begin{array}{l}\text { 5'LCRed640-CTGTCTGTGGCCCCAGGAACCCTGCTTATCTAGTT- } \\
\text { 3'phosphate }\end{array}$ \\
\hline & & & & Sensor probe & 5'-TGAGTATTGGGAATGCGCAGG-3'Fluorescein \\
\hline \multirow[t]{4}{*}{3} & Fok İ & rsiôj358io & $\dot{A} / \bar{G}$ & Sense primer & 5'CGTTCCGGTCAAAGTCTCC-3' \\
\hline & & & (ambiguity code: $\mathrm{R}$ ) & Antisense primer & 5'-TTGCTGAGCTCCCTGGTG-3' \\
\hline & & & & Anchor probe & 5'LCRed640-GGACGGAGGCAATGGCG-3'phosphate \\
\hline & & & & Sensor probe & 5'-GCTCTGACCGTGGCCTGCTTGCTGTTCTTACA-3'Fluorescein \\
\hline
\end{tabular}

VDR, vitamin D receptor; SNP, single-nucleotide polymorphism

PCR was performed with $0.5 \mu \mathrm{M}$ sense primer and $0.05 \mu \mathrm{M}$ antisense primer in a reaction mixture containing $0.2 \mu \mathrm{M}$ anchor probe, $0.2 \mu \mathrm{M}$ sensor probe, $10 \mathrm{ng}$ dried DNA, $4.0 \mu \mathrm{M} \mathrm{MgCl}_{2}, 0.5 \mu \mathrm{l} 10 \times$ PCR buffer, $0.2 \mathrm{mM}$ dNTP, and $0.5 \mathrm{U}$ of Faststart DNA polymerase (Roche Diagnostics) in a total volume of 5 $\mu 1$. The cycling program consisted of an initial denaturation for $10 \mathrm{~min}$ at $94^{\circ} \mathrm{C}, 40$ cycles of $15 \mathrm{~s}$ at $94^{\circ} \mathrm{C}, 55^{\circ} \mathrm{C}$ for $15 \mathrm{~s}$, and $72^{\circ} \mathrm{C}$ for $15 \mathrm{~s}$, followed by a final extension for $2 \mathrm{~min}$ at $72^{\circ} \mathrm{C}$.

After PCR, the reaction products were denatured at $94^{\circ} \mathrm{C}$ for $60 \mathrm{~s}$, annealed at $40^{\circ} \mathrm{C}$ for $60 \mathrm{~s}$, and melted by heating from 40 to $80^{\circ} \mathrm{C}$ at a rate of $0.1^{\circ} \mathrm{C} / \mathrm{s}$. The melt curve data were collected and classified using the LightTyper genotyping software, and genotypes were determined. The absence or presence of the ApaI, BsmI, and FokI sites were designated as A, B, and F alleles and $\mathrm{a}, \mathrm{b}$, and $\mathrm{f}$ alleles, respectively.

\section{Statistical analysis}

The frequency of each of the three polymorphisms was tested against Hardy-Weinberg equilibrium using the $\chi^{2}$ test, which was also used to compare categorical variables. Differences in the anthropometric characteristics of the different VDR genotypes or haplotypes were compared using one-way analysis of variance. To calculate the odds ratios (ORs) and 95\% confidence intervals (CIs), multiple logistic regression analysis was performed to quantify the association between severe chronic periodontitis and the VDR polymorphisms after adjusting for age, smoking status, number of teeth present, and prevalence of diabetes.

A value of $p<0.05$ was considered statistically significant for all analyses. All statistical analyses were performed using the Statistical Package for the Social Sciences Version 11 for Windows (SPSS Inc., Chicago,
IL).

\section{RESULTS}

\section{Single nucleotide polymorphisms}

Table 2 shows the demographic features of the participants with the polymorphisms. The genotype frequency of each of the VDR ApaI, BsmI, and FokI polymorphisms was consistent with Hardy-Weinberg equilibrium. The most frequent genotypes of the ApaI, $B s m \mathrm{I}$, or FokI polymorphisms were AA, bb, and Ff, respectively. No one had the BB genotype of the BsmI polymorphism. No statistically significant differences were detected in age, BMI, the percentage of current smokers, the percentage of individuals suffering from diabetes, or clinical indicators for oral status and the three genotypes. The study subjects included 42 current smokers $(43.3 \%)$ and 2 diabetics $(2.1 \%)$.

The distribution of the CPI scores between 0 and 4 were $13.4,15.5,14.4,39.2$, and $17.5 \%$, respectively. Seventeen subjects were diagnosed with severe chronic periodontitis. While the mean $( \pm S D)$ percentage of teeth with bleeding on probing and the mean $( \pm S D)$ probing depth were $72.6 \pm 29.3 \%$ and $4.0 \pm 0.8 \mathrm{~mm}$, respectively, among subjects with severe chronic periodontitis, those figures were 37.2 $\pm 32.5 \%$ and $2.6 \pm 0.6 \mathrm{~mm}$ among subjects without severe chronic periodontitis. No statistically significant differences were found in the mean $( \pm S D)$ number of teeth present between subjects with and without severe chronic periodontitis $(25.7 \pm 2.1$ and $25.3 \pm 4.4$, respectively).

The FokI genotype and allele frequencies differed between the groups with and without severe chronic periodontitis (Table 3). Individuals with any genotype that contained the $\mathrm{F}$ allele were less likely to develop severe chronic periodontitis than those with the ff genotype $(p=0.09)$. Furthermore, heterozygous Ff individuals had a lower risk of severe chronic 
periodontitis than individuals who lacked the $\mathrm{F}$ allele $(\mathrm{OR}=0.25 ; 95 \% \mathrm{CI}=0.06-0.95)$. The ApaI and BsmI polymorphisms did not show statistically significant differences in alleles or genotypes between the groups with or without severe chronic periodontitis.

\section{Combined polymorphisms}

Seven different haplotypes were identified after analyzing combinations of the genotype frequencies for the three VDR polymorphisms: $\mathrm{Abf}(39.2 \%), \mathrm{AbF}$ $(28.4 \%)$, abF (13.4\%), abf (9.3\%), aBf (6.7\%), Abf (2.6\%), and aBF $(0.5 \%)$ (Table 4$)$. These haplotypes combined to form 16 different genotypes, of which the most prevalent were AAbbFf (20.6\%), AAbbff (13.4\%), AAbbFF (12.4\%), AabbFf (11.3\%), and Aabbff (10.3\%). The Abf haplotype was more common in individuals with severe chronic periodontitis than in those who did not have the disease. Moreover, the abF haplotype was less prevalent in individuals with severe chronic periodontitis than in those without severe chronic periodontitis.

Table 5 shows the association between individuals who were carrying combined VDR polymorphisms and the prevalence of severe chronic periodontitis. For this purpose, the data obtained from participants possessing the most common haplotypes (Abf, AbF, and abF) were analyzed. The Abf homozygous individuals had a significantly higher prevalence of severe chronic periodontitis than the others, and adjustments for age, smoking status, number of teeth present, and prevalence of diabetes did not change this association $(\mathrm{OR}=7.5 ; 95 \% \mathrm{CI}=$ 1.6-34.4; $p=0.01$ ). After adjusting for age or for all covariates, the $\mathrm{AbF}$ homozygote had a higher prevalence of severe chronic periodontitis than the others, and the abF haplotype had a lower prevalence of severe chronic periodontitis. However, the differences among the groups were not statistically significant.

Table 2. Characteristics of the study subjects according to the genotypes of the Apa I, Bsm I, and Fok I VDR polymorphisms

\begin{tabular}{|c|c|c|c|c|c|c|c|c|c|c|c|c|}
\hline \multirow[b]{2}{*}{ Characteristic } & \multicolumn{4}{|c|}{ Apa I } & \multicolumn{4}{|c|}{$B s m \mathrm{I}$} & \multicolumn{4}{|c|}{ Fok I } \\
\hline & AA & $\mathrm{Aa}$ & aa & $\mathrm{p}$ & $\mathrm{bb}$ & $\mathrm{Bb}$ & BB & $\mathrm{p}$ & $\mathrm{ff}$ & $\mathrm{Ff}$ & $\mathrm{FF}$ & $\mathrm{p}$ \\
\hline $\mathrm{N}$ & 50 & 36 & 11 & & 78 & 19 & 0 & & 34 & 44 & 19 & \\
\hline Age $( \pm \mathrm{SD})$ (years) & $47.0 \pm 11.0$ & $45.1 \pm 11.7$ & $41.7 \pm 11.7$ & 0.34 & $46.0 \pm 11.1$ & $44.9 \pm 12.6$ & - & 0.77 & $46.0 \pm 11.4$ & $45.8 \pm 45.0$ & $45.2 \pm 10.7$ & 0.98 \\
\hline Budy mass index $( \pm \mathrm{SD})\left(\mathrm{kg} / \mathrm{mi}^{2}\right)$ & $23.5 \perp 3.0$ & $22.9 \pm 3.3$ & $23.4+3.5$ & 0.69 & $23.3+3.1$ & $23.0+3.3$ & - & 0.69 & $22.9 \perp 2.7$ & $23.5+3.5$ & $23.4+3.0$ & 0.71 \\
\hline Current smoker (\%) & 50.0 & 41.9 & 60.0 & 0.78 & 48.6 & 46.7 & - & 0.70 & 44.8 & 53.7 & 41.2 & 0.12 \\
\hline $\mathrm{N}$ with diabetes $(\%)$ & 4.0 & 0.0 & 0.0 & 0.38 & 1.3 & 5.3 & - & 0.27 & 2.9 & 0.0 & 5.3 & 0.36 \\
\hline $\mathrm{N}$ teeth present $( \pm \mathrm{SD})$ & $25.2 \pm 4.1$ & $25.1 \pm 4.6$ & $26.9 \pm 1.1$ & 0.41 & $25.6 \pm 3.3$ & $24.4 \pm 6.5$ & - & 0.25 & $25.2 \pm 3.9$ & $25.3 \pm 4.9$ & $25.7 \pm 2.6$ & 0.90 \\
\hline$\%$ teeth with beleeding on probing $( \pm \mathrm{SD})$ & $42.7 \pm 35.8$ & $46.6 \pm 33.3$ & $35.8 \pm 34.9$ & 0.65 & $42.4 \pm 34.9$ & $47.2 \pm 33.7$ & - & 0.59 & $40.0 \pm 31.9$ & $44.1 \pm 34.4$ & $47.7 \pm 40.5$ & 0.73 \\
\hline Average probing depth $( \pm \mathrm{SD})(\mathrm{mm})$ & $3.0 \pm 0.9$ & $2.7 \pm 0.7$ & $2.7 \pm 0.8$ & 0.25 & $2.8 \pm 0.8$ & $2.9 \pm 0.9$ & - & 0.89 & $2.8 \pm 0.79$ & $2.9 \pm 0.80$ & $2.9 \pm 1.1$ & 0.90 \\
\hline
\end{tabular}

VDR, vitamin D receptor; SD, standard deviation

Table 3. Genotype and allele frequencies of Apa I, Bsm I, and Fok I VDR polymorphisms in subjects with and without severe chronic periodontitis

\begin{tabular}{|c|c|c|c|c|c|c|c|c|}
\hline \multirow{2}{*}{ SNP } & \multirow{2}{*}{ Genotype } & \multicolumn{2}{|c|}{$\begin{array}{l}\text { Severe chronic } \\
\text { periodontitis }\end{array}$} & \multicolumn{2}{|c|}{$\begin{array}{l}\text { No severe chronic } \\
\text { periodontitis }\end{array}$} & \multirow{2}{*}{$\mathrm{OR}^{\dagger}$} & \multirow{2}{*}{$95 \% \mathrm{CI}$} & \multirow{2}{*}{$\mathrm{p}$} \\
\hline & & $\mathrm{N}$ & (\%) & $\mathrm{N}$ & $(\%)$ & & & \\
\hline \multirow[t]{5}{*}{$\overline{A p a \mathrm{I}}$} & AA & 12 & (70.6) & 38 & (47.5) & 1 & reference & 0.17 \\
\hline & $\mathrm{Aa}$ & 3 & $(17.6)$ & 33 & (41.3) & 0.30 & $0.07-1.19$ & \\
\hline & aa & 2 & (11.8) & 9 & (11.3) & 1.12 & $0.19-6.83$ & \\
\hline & $\mathrm{Aa} / \mathrm{aa}$ & 5 & (29.4) & 42 & $(52.5)$ & 0.42 & $0.13-1.38$ & $0.15^{*}$ \\
\hline & A & \multicolumn{2}{|c|}{0.76} & \multicolumn{2}{|c|}{0.68} & & & \\
\hline \multirow[t]{5}{*}{ Bsm I } & $\mathrm{bb}$ & 13 & $(76.5)$ & 65 & (81.3) & 1 & reference & 0.65 \\
\hline & $\mathrm{Bb}$ & 4 & $(23.5)$ & 15 & (18.8) & 1.38 & $0.36-5.28$ & \\
\hline & $\mathrm{BR}$ & 0 & $(0.0)$ & 0 & $(0.0)$ & - & - & \\
\hline & $\mathrm{BB} / \mathrm{Bb}$ & 4 & $(23.5)$ & 15 & (18.8) & 1.38 & $0.36-5.28$ & $0.65^{*}$ \\
\hline & $\mathrm{b}$ & \multicolumn{2}{|c|}{0.88} & \multicolumn{2}{|c|}{0.91} & & & \\
\hline \multirow[t]{5}{*}{ Fok I } & $\mathrm{ff}$ & 9 & (52.9) & 25 & (31.3) & 1 & reference & 0.12 \\
\hline & $\mathrm{Ff}$ & 4 & (23.5) & 40 & $(50.0)$ & 0.25 & $0.06-0.95$ & \\
\hline & $\mathrm{FF}$ & 4 & (23.5) & 15 & (18.8) & 0.79 & $0.19-3.34$ & \\
\hline & $\mathrm{Ff} / \mathrm{FF}$ & 8 & (47.1) & 55 & $(68.8)$ & 0.38 & $0.12-1.18$ & $0.09^{*}$ \\
\hline & f & \multicolumn{2}{|c|}{0.65} & \multicolumn{2}{|c|}{0.44} & & & \\
\hline
\end{tabular}

$\dagger$ Adjusted for age

$\ddagger \chi^{2}$ analysis (a carrier, $B$ carrier, or $F$ carrier versus each reference)

VDR, vitamin D receptor; SNP, single-nucleotide polymorphism; OR, odds ratio; CI, confidence Interval 
Int. J. Med. Sci. 2007, 4

Table 4. Haplotype and genotype frequencies of the Apa I, BsmI, and Fok I VDR polymorphisms

\begin{tabular}{|c|c|c|c|c|c|c|c|c|c|}
\hline \multirow[t]{2}{*}{ Haplotype } & \multicolumn{2}{|c|}{$\begin{array}{l}\text { Severe chronic } \\
\text { periodontitis }\end{array}$} & \multicolumn{2}{|c|}{$\begin{array}{l}\text { No severe chronic } \\
\text { periodontitis }\end{array}$} & \multirow[t]{2}{*}{ Genotype } & \multicolumn{2}{|c|}{$\begin{array}{l}\text { Severe chronic } \\
\text { periodontitis }\end{array}$} & \multicolumn{2}{|c|}{$\begin{array}{l}\text { No severe chronic } \\
\text { periodontitis }\end{array}$} \\
\hline & $\mathrm{N}$ & $(\%)$ & $\mathrm{N}$ & $(\%)$ & & $\mathrm{N}$ & $(\%)$ & $\mathrm{N}$ & $(\%)$ \\
\hline $\mathrm{Abf}$ & 15 & $(44.1)$ & 61 & $(38.1)$ & $\mathrm{Abf} / \mathrm{AbF}$ & 2 & $(11.8)$ & 18 & $(22.5)$ \\
\hline $\mathrm{AbF}$ & 10 & (29.4) & 45 & $(28.1)$ & $\mathrm{Abf} / \mathrm{Abf}$ & 5 & $(29.4)$ & 8 & (10.0) \\
\hline$a b F$ & 2 & $(5.9)$ & 24 & $(15.0)$ & $\mathrm{AbF} / \mathrm{AbF}$ & 3 & $(17.6)$ & 9 & (11.3) \\
\hline$a b f$ & 3 & (8.8) & 15 & (9.4) & Abf/abF & 0 & $(0.0)$ & 11 & (13.8) \\
\hline $\mathrm{aBf}$ & 2 & (5.9) & 11 & (6.9) & Abf/abf & 1 & (5.9) & 9 & (11.3) \\
\hline $\mathrm{ABf}$ & 2 & (5.9) & 3 & (1.9) & $\mathrm{Abf} / \mathrm{aBf}$ & 1 & (5.9) & 5 & (6.3) \\
\hline \multirow[t]{10}{*}{$\mathrm{aBF}$} & 0 & $(0.0)$ & 1 & $(0.6)$ & $\mathrm{abF} / \mathrm{abf}$ & 1 & (5.9) & 4 & $(5.0)$ \\
\hline & & & & & $\mathrm{AbF} / \mathrm{aBf}$ & 0 & $(0.0)$ & 4 & $(5.0)$ \\
\hline & & & & & $\mathrm{AbF} / \mathrm{abF}$ & 1 & (5.9) & 3 & (3.8) \\
\hline & & & & & $\mathrm{Abf} / \mathrm{ABf}$ & 1 & (5.9) & 2 & (2.5) \\
\hline & & & & & $\mathrm{aBf} / \mathrm{abF}$ & 0 & $(0.0)$ & 2 & $(2.5)$ \\
\hline & & & & & $\mathrm{abF} / \mathrm{abF}$ & 0 & $(0.0)$ & 2 & $(2.5)$ \\
\hline & & & & & $\mathrm{ABf} / \mathrm{AbF}$ & 1 & (5.9) & 1 & (1.3) \\
\hline & & & & & $\mathrm{AbF} / \mathrm{aBF}$ & 0 & $(0.0)$ & 1 & (1.3) \\
\hline & & & & & abffabf & 0 & $(0.0)$ & 1 & (1.3) \\
\hline & & & & & aBf/abf & 1 & (5.9) & 0 & $(0.0)$ \\
\hline Total & 34 & $(100.0)$ & 160 & $(100.0)$ & Total & 17 & $(100.0)$ & 80 & $(100.0)$ \\
\hline
\end{tabular}

VDR, vitamin D receptor

Table 5. Associations between the combined Apa I, Bsm I, and Fok I VDR polymorphisms and severe chronic periodontitis risk

\begin{tabular}{|c|c|c|c|c|c|c|c|c|c|c|}
\hline \multirow[t]{2}{*}{ Abf Genotype } & \multicolumn{2}{|c|}{$\begin{array}{c}\text { Severe chronic } \\
\text { periodontitis }\end{array}$} & \multicolumn{2}{|c|}{$\begin{array}{c}\text { No severe chronic } \\
\text { periodontitis }\end{array}$} & \multirow[t]{2}{*}{$\mathrm{OR}^{\dagger}$} & \multirow[t]{2}{*}{$95 \% \mathrm{CI}$} & \multirow[t]{2}{*}{$\mathrm{p}$} & \multirow[t]{2}{*}{$\mathrm{OR}^{\dagger \dagger}$} & \multirow[t]{2}{*}{$95 \% \mathrm{CI}$} & \multirow[t]{2}{*}{$\mathrm{p}$} \\
\hline & $\mathrm{N}$ & $\%$ & $\mathrm{~N}$ & $\%$ & & & & & & \\
\hline Abf 0 or 1 copyy & 12 & $(70.6)$ & 72 & $(90.0)$ & 1 & referentice & 0.02 & 1 & referentice & 0.01 \\
\hline Abf 2copies & 5 & (29.4) & 8 & $(10.0)$ & 5.93 & $1.30-27.13$ & & 7.47 & $1.62-34.39$ & \\
\hline \multirow[t]{2}{*}{ AbF Genotype } & \multicolumn{2}{|c|}{$\begin{array}{c}\text { Severe chronic } \\
\text { periodontitis }\end{array}$} & \multicolumn{2}{|c|}{$\begin{array}{c}\text { No severe chronic } \\
\text { periodontitis }\end{array}$} & \multirow[t]{2}{*}{$\mathrm{OR}^{\dagger}$} & \multirow[t]{2}{*}{$95 \% \mathrm{CI}$} & \multirow[t]{2}{*}{$\mathrm{p}$} & \multirow[t]{2}{*}{$\mathrm{OR}^{1 \dagger}$} & \multirow[t]{2}{*}{$95 \% \mathrm{CI}$} & \multirow[t]{2}{*}{$\mathrm{p}$} \\
\hline & $\mathrm{N}$ & $\%$ & $\mathrm{~N}$ & $\%$ & & & & & & \\
\hline $\mathrm{AbF} 0$ or 1 copy & 14 & $(82.4)$ & 71 & $(88.8)$ & 1 & reference & 0.65 & 1 & reference & 0.84 \\
\hline AbF 2copies & 3 & $(17.6)$ & 9 & (11.3) & 1.41 & $0.31-6.31$ & & 1.20 & $0.21-6.89$ & \\
\hline \multirow[t]{2}{*}{ abF Genotype } & \multicolumn{2}{|c|}{$\begin{array}{c}\text { Severe chronic } \\
\text { periodontitis }\end{array}$} & \multicolumn{2}{|c|}{$\begin{array}{c}\text { No severe chronic } \\
\text { periodontitis }\end{array}$} & \multirow[t]{2}{*}{$\mathrm{OR}^{\dagger}$} & \multirow[t]{2}{*}{$95 \% \mathrm{CI}$} & \multirow[t]{2}{*}{$\mathrm{p}$} & \multirow[t]{2}{*}{$\mathrm{OR}^{\dagger \dagger}$} & \multirow[t]{2}{*}{$95 \% \mathrm{CI}$} & \multirow[t]{2}{*}{$\mathrm{p}$} \\
\hline & $\mathrm{N}$ & $\%$ & $\mathrm{~N}$ & $\%$ & & & & & & \\
\hline abF 0copy & 15 & $(88.2)$ & 58 & $(72.5)$ & 1 & reference & 0.39 & 1 & reference & 0.22 \\
\hline abF $\bar{I}$ copy or Zcopies & 2 & (ill $11 . \overline{8})$ & 22 & $(27.5)$ & 0.49 & $0.10-2.47$ & & 0.26 & $0.03-2.22$ & \\
\hline
\end{tabular}

$\dagger$ Adjusted for age

†† Adjusted for age, smoking status, number of teeth present, and prevalence of diabetes

$\mathrm{VDR}$, vitamin D receptor; OR, odds ratio; $\mathrm{CI}$, confidence interval

\section{DISCUSSION}

We examined the relationship between ApaI, BsmI, and FokI VDR polymorphisms and severe chronic periodontitis in Japanese males. We determined that haplotypes of these three polymorphisms were related to the prevalence of severe chronic periodontitis, while no statistically significant associations were found in the analysis of 
individual polymorphisms. A single case-control study has been conducted [25], which revealed that the VDR haplotype constructed from the TaqI, BsmI, and FokI VDR polymorphisms was correlated with an increased risk of periodontitis. To our knowledge, this is the first study to examine the association between periodontitis and haplotypes of the ApaI, BsmI, and FokI VDR polymorphisms.

Two previous studies on BsmI VDR polymorphisms conducted among Japanese [36] and Brazilian populations [37] found no statistically significant differences in the distribution of the BsmI VDR polymorphism between individuals with and without periodontal disease. Our data support those findings. Inagaki et al. [26] demonstrated an association between the ApaI VDR polymorphism and the progress of periodontal disease in adult men who participated in the Dental Longitudinal Study in the United States. Specifically, they reported that the loss of alveolar bone and clinical attachment occurred at the highest rate in the AA genotype of the ApaI VDR polymorphism compared to the Aa or aa genotypes. We found that the AA genotype was more likely to increase the risk of severe chronic periodontitis, although the differences among the genotypes were not statistically significant.

Park et al. [25] indicated an association between the FokI VDR polymorphism and an increased risk of developing generalized aggressive periodontitis, whereas Tachi et al. [38] did not find such an association. Among the haplotypes of the three polymorphic sites, the Abf homozygote showed that a VDR allele positively affected the prevalence of severe chronic disease. The ff genotype of the FokI VDR polymorphism has been reported to convey stronger bone resorption and inflammation signals [25]. In our study, the F allele of the FokI VDR polymorphism was less likely to increase the risk of severe chronic periodontitis. This may support the proposal of Park et al. [25] that the FokI VDR polymorphism plays an important role in increasing the risk of developing periodontitis.

Our findings suggest an important possibility when interpreting studies on the prevention of periodontitis for a parameter that generally has not been considered. In a series aimed at describing the clinical and microbial features over time in periodontal healthy adult subjects who received primary prevention, Bogren et al. [39] reported that the overall changes in clinical parameters were limited during a 3-year controlled trial with primary prevention for periodontitis. Although this study had limitations, such as a small sample size and cross-sectional study design, the data suggest that the combined VDR polymorphisms can predict periodontitis. Analyzing the combined VDR polymorphisms has the potential to guide individualized prevention and therapy; thus, further studies for confirmation are needed.

Accumulated evidence indicates that diabetes is a major risk factor for periodontitis, and severe periodontitis often coexists with diabetes [40]. Taylor et al. [41] concluded that diabetics have a three- to fourfold increased risk of periodontitis. In addition, smoking has been established as the most important environmental risk factor for periodontitis [30], and cigarette smoking is a strong predictor of progressive periodontitis [31,32]. Cesar-Neto et al. [42] demonstrated that smoking modulated gene expression of cytokines in the periodontium, such as interleukin (IL)-6 and IL-10. The association between the Abf haplotype and periodontal disease that we observed was independent of current smoking status and the prevalence of diabetes as a statistical adjustment did not diminish the influence of the VDR haplotype on periodontal disease status. In fact, adjusting for those factors did not weaken this association.

While we report a relationship between the VDR haplotype and periodontal disease, it remains unclear whether this association is valid among females, non-Asians, or people aged 60 years or more. Studies with larger sample size are also necessary for further discussion. When only the individual polymorphisms were analyzed and the haplotypes were not considered, these effects were not noticed [10]. Clearly, additional studies are needed to determine whether the combined VDR polymorphisms influence the risk of developing periodontitis under various settings.

In conclusion, the VDR haplotype constructed from the ApaI, BsmI, and FokI VDR polymorphisms is related to the prevalence of severe chronic periodontitis in Japanese men. Analysis of VDR haplotype alleles may be useful for predicting the risk of developing periodontal disease. Further studies in gender-, ethnic-, or age-specific groups are needed.

\section{CONFLICTS OF INTEREST}

The authors declare that no conflict of interest exists.

\section{REFERENCES}

1. Michalowicz BS, Aeppli D, Virag JG, et al. Periodontal findings in adult twins. J Periodontol. 1991; 62: 293-299.

2. D'Ambrosio D, Cippitelli M, Cocciolo MG, et al. Inhibition of IL-12 production by 1,25-dihydroxyvitamin D3. Involvement of NF-kappaB downregulation in transcriptional repression of the p40 gene. J Clin Invest. 1998; 101: 252-262.

3. Krall EA, Wehler C, Garcia RI, et al. Calcium and vitamin D supplements reduce tooth loss in the elderly. Am J Med. 2001; 111: 452-456.

4. Dietrich T, Joshipura KJ, Dawson-Hughes B, et al. Association between serum concentrations of 25-hydroxyvitamin D3 and periodontal disease in the US population. Am J Clin Nutr. 2004; 80: 108-113.

5. Specker BL, Ho ML, Oestreich A, et al. Prospective study of vitamin D supplementation and rickets in China. J Pediatr. 1992; 120: 733-739.

6. Payne JB, Reinhardt RA, Nummikoski PV, et al. Longitudinal alveolar bone loss in postmenopausal osteoporotic/osteopenic women. Osteoporos Int. 1999; 10: 34-40.

7. Tezal M, Wactawski-Wende J, Grossi SG, et al. The relationship between bone mineral density and periodontitis in postmenopausal women. J Periodontol. 2000; 71: 1492-1498. 
8. Dervis E. Oral implications of osteoporosis. Oral Surg Oral Med Oral Pathol Oral Radiol Endod. 2005; 100: 349-356.

9. Wactawski-Wende J. Periodontal diseases and osteoporosis: association and mechanisms. Ann Periodontol. 2001; 6: 197-208.

10. Uitterlinden AG, Fang Y, Van Meurs JB, et al. Genetics and biology of vitamin D receptor polymorphisms. Gene. 2004; 338: 143-156.

11. Ye WZ, Reis AF, Velho G. Identification of a novel Tru9 I polymorphism in the human vitamin $\mathrm{D}$ receptor gene. J Hum Genet. 2000; 45: 56-57.

12. Morrison NA, Qi JC, Tokita A, et al. Prediction of bone density from vitamin D receptor alleles. Nature. 1994; 367: 284-287.

13. Morrison NA, Yeoman R, Kelly PJ, et al. Contribution of trans-acting factor alleles to normal physiological variability: vitamin D receptor gene polymorphism and circulating osteocalcin. Proc Natl Acad Sci USA. 1992; 89: 6665-6669.

14. Faraco JH, Morrison NA, Baker A, et al. ApaI dimorphism at the human vitamin D receptor gene locus. Nucleic Acids Res. 1989; 17: 2150

15. Gross C, Eccleshall TR, Malloy PJ, et al. The presence of a polymorphism at the translation initiation site of the vitamin D receptor gene is associated with low bone mineral density in postmenopausal Mexican-American women. J Bone Miner Res. 1996; 11: 1850-1855.

16. Saijo $\mathrm{T}$, Ito $\mathrm{M}$, Takeda $\mathrm{E}$, et al. A unique mutation in the vitamin $\mathrm{D}$ receptor gene in three Japanese patients with vitamin D-dependent rickets type II: utility of single-strand conformation polymorphism analysis for heterozygous carrier detection. Am J Hum Genet. 1991; 49: 668-673.

17. Arai H, Miyamoto KI, Yoshida M, et al. The polymorphism in the caudal-related homeodomain protein $\mathrm{Cdx}-2$ binding element in the human vitamin D receptor gene. J Bone Miner Res. 2001; 16: 1256-1264.

18. Sezer S, Tutal E, Bilgic A, et al. Possible influence of vitamin D receptor gene polymorphisms on recombinant human erythropoietin requirements in dialysis patients. Transplant Proc. 2007; 39: 40-44.

19. Moon S, Holley S, Bodiwala D, et al. Associations between G/A1229, A/G3944, T/C30875, C/T48200 and C/T65013 genotypes and haplotypes in the vitamin $\mathrm{D}$ receptor gene, ultraviolet radiation and susceptibility to prostate cancer. Ann Hum Genet. 2006; 70: 226-236.

20. Zhou W, Heist RS, Liu G, et al. Polymorphisms of vitamin D receptor and survival in early-stage non-small cell lung cancer patients. Cancer Epidemiol Biomarkers Prev. 2006; 15: 2239-2245.

21. Murtaugh MA, Sweeney C, Ma KN, et al. Vitamin D receptor gene polymorphisms, dietary promotion of insulin resistance, and colon and rectal cancer. Nutr Cancer. 2006; 55: 35-43.

22. Bid HK, Kumar A, Kapoor R, et al. Association of vitamin D receptor-gene (FokI) polymorphism with calcium oxalate nephrolithiasis. J Endourol. 2005; 19: 111-115.

23. Sun JL, Meng HX, Cao CF, et al. Relationship between vitamin $\mathrm{D}$ receptor gene polymorphism and periodontitis. J Periodontal Res. 2002; 37: 263-267.

24. Brett PM, Zygogianni P, Griffiths GS, et al. Functional gene polymorphisms in aggressive and chronic periodontitis. J Dent Res. 2005; 84: 1149-1153.

25. Park KS, Nam JH, Choi J. The short vitamin D receptor is associated with increased risk for generalized aggressive periodontitis. J Clin Periodontol. 2006; 33: 524-528.

26. Inagaki K, Krall EA, Fleet JC, et al. Vitamin D receptor alleles, periodontal disease progression, and tooth loss in the VA dental longitudinal study. J Periodontol. 2003; 74: 161-167.

27. Jaramillo-Rangel G, Cerda-Flores RM, Cardenas-Ibarra L, et al. Vitamin D receptor polymorphisms and bone mineral density in Mexican women without osteoporosis. Am J Hum Biol. 1999; 11:
793-797.

28. Kim JG, Kwon JH, Kim SH, et al. Association between vitamin $\mathrm{D}$ receptor gene haplotypes and bone mass in postmenopausal Korean women. Am J Obstet Gynecol. 2003; 189: 1234-1240.

29. Macdonald HM, McGuigan FE, Stewart A, et al. Large-scale population-based study shows no evidence of association between common polymorphism of the VDR gene and BMD in British women. J Bone Miner Res. 2006; 21: 151-162.

30. Borrell LN, Papapanou PN. Analytical epidemiology of periodontitis. J Clin Periodontol. 2005; 32: 132-158.

31. Heitz-Mayfield LJ. Disease progression: identification of high-risk groups and individuals for periodontitis. J Clin Periodontol. 2005; 32: 196-209.

32. Razali M, Palmer RM, Coward P, et al. A retrospective study of periodontal disease severity in smokers and non-smokers. Br Dent J. 2005; 198: 495-498.

33. Hanioka T, Ojima M, Tanaka K, et al. Association of total tooth loss with smoking, drinking alcohol and nutrition in elderly Japanese: analysis of national database. Gerodontology. 2007; 24: 87-92.

34. Miyaki K, Masaki K, Naito M, et al. Periodontal disease and atherosclerosis from the viewpoint of the relationship between community periodontal index of treatment needs and brachial-ankle pulse wave velocity. BMC Public Health. 2006; 6: 131 .

35. Bennett CD, Campbell MN, Cook CJ, et al. The LightTyper: high-throughput genotyping using fluorescent melting curve analysis. Biotechniques. 2003; 34: 1288-1292.

36. Yoshihara A, Sugita N, Yamamoto K, et al. Analysis of vitamin $\mathrm{D}$ and Fcgamma receptor polymorphisms in Japanese patients with generalized early-onset periodontitis. J Dent Res. 2001; 80: 2051-2054.

37. de Brito Junior RB, Scarel-Caminaga RM, Trevilatto PC, et al. Polymorphisms in the vitamin $\mathrm{D}$ receptor gene are associated with periodontal disease. J Periodontol. 2004; 75: 1090-1095.

38. Tachi Y, Shimpuku H, Nosaka Y, et al. Vitamin D receptor gene polymorphism is associated with chronic periodontitis. Life Sci. 2003; 73: 3313-3321.

39. Bogren A, Teles R, Torresyap G, et al. A three-year prospective study of adult subjects with gingivitis. I: clinical periodontal parameters. J Clin Periodontol. 2007; 34: 1-6.

40. Löe H. Periodontal disease. The sixth complication of diabetes mellitus. Diabetes Care. 1993; 16: 329-334.

41. Taylor GW, Burt BA, Becker MP, et al. Non-insulin dependent diabetes mellitus and alveolar bone loss progression over 2 years. J Periodontol. 1998; 69: 76-83.

42. Cesar-Neto JB, Duarte P M, de Oliveira MC, et al. Smoking modulates interleukin-6:interleukin-10 and RANKL: osteoprotegerin ratios in the periodontal tissues. J Periodontal Res. 2007; 42: 184-191. 